\title{
Interstitial 14q24.3 to q31.3 deletion in a 6-year-old boy with a non-specific dysmorphic phenotype
}

\author{
Mariluce Riegel ${ }^{1,2,3^{*}}$, Lilia MA Moreira ${ }^{4}$, Layla D Espirito Santo ${ }^{4}$, Maria Betânia P Toralles ${ }^{5}$ and Albert Schinzel ${ }^{3}$
}

\begin{abstract}
Background: Few patients with interstitial deletions in the distal long arm of chromosome 14 have been reported, and these patients showed rather indistinct features, including growth and mental retardation and phenotypic alterations.

Results: We describe a de novo 14q interstitial deletion in a 6-year-old boy with dysmorphic facial traits such as hypertelorism, short and narrow palpebral fissures, broad nose with anteverted nostrils, long philtrum, thin upper lip with cupid's bow, prominent and everted lower lip, mildly low-set ears, as well as moderate developmental delay and mild mental retardation. Array-CGH mapped the deletion to the region 14q24.3 to 14q31.3, including $13.11 \mathrm{Mb}$, proximal to the imprinted genomic region of $14 q 32$.

Conclusion: This mild phenotypic presentation suggests that the deleted segment does not contain essential genes for early organ development. Twenty-two genes with known functions, including Neurexin III (NRXN3, OMIM 600567), map to the region deleted in the propositus.
\end{abstract}

Keywords: Genotype-phenotype correlation, 14q interstitial deletion, Array-CGH

\section{Background}

The few reported patients with interstitial microdeletions in the long arm of chromosome 14 have shown a broad and inconsistent spectrum of clinical features caused by loss of different segments of 14q. An understanding of the phenotypes of these clinical disorders is further hampered by the scarcity of reports and the fact that most of the reported patients were diagnosed using only traditional chromosome banding with inaccurate and approximate mapping of the deleted segment.

Cingöz et al. [1], considering the minimal size of these deletions in 11 patients, constructed a map for the three shortest regions of deletion overlap. The proximal region includes the gene encoding Neurexin III (NRXN3, MIM 600567), for which haploinsufficiency is associated with cognitive and neurological defects.

Here, we report a male patient with a de novo deletion of the segment $14 \mathrm{q} 24.3$ to $\mathrm{q} 31.3$, determined using

\footnotetext{
* Correspondence: mriegel@hcpa.ufrgs.br

'Medical Genetics Service, Hospital de Clínicas de Porto Alegre, Rua Ramiro Barcelos 2350, 90035-003 Porto Alegre, RS, Brazil

${ }^{2}$ Postgraduate Program in Genetics and Molecular Biology, UFRGS, Porto Alegre, RS, Brazil

Full list of author information is available at the end of the article
}

comparative genomic hybridization with microarray (array $\mathrm{CGH}$; aCGH). We also sought to correlate the clinical findings to those of patients with deletions overlapping that identified in the propositus. Considering that breakpoint determination using only banded karyotypes is not precise and may be inaccurate, we included only reports with molecular determination or confirmation of the breakpoints in our comparison.

\section{Case presentation}

The patient was a male aged 6 years and 9 months, the only son of a 38-year-old mother and a 41-year-old father who measured $1.58 \mathrm{~m}$ and $1.76 \mathrm{~m}$ in height, respectively, and were healthy and nonconsanguineous. The parents reported no genetic conditions or birth defects in the family. The pregnancy was planned and uneventful. Delivery was by cesarean section at 39 weeks and 6 days. The patient's birth weight was $3145 \mathrm{~g}$, with a length of $49 \mathrm{~cm}$ and head circumference of $33.5 \mathrm{~cm}$, which are all appropriate for the gestational age. There was no visible perinatal asphyxia. The postnatal course was characterized by psychomotor delay and muscular hypotonia.

At the first clinical evaluation at 20 months of age, he showed mild dysmorphic features. The first tooth erupted 
at 8 months of age. Beginning at 6 months of age, he received regular neurological and pediatric follow-ups. The first smile was noted at the age of 2 months, rolling from a ventral to a dorsal position was observed at 3 months, following objects with his eyes was observed at 6 months, maintaining a sitting position was observed at 8 months, maintaining a standing position was observed at 10 months, responding to his name was observed at 10 months, walking was observed at 20 months, and toilet training was achieved at $2 \frac{1}{2}$ years.

At 6 months of age, physical therapy and an interdisciplinary program of early stimulation were initiated. He was discharged from physical therapy at the end of the second year of life. Psychologic evaluation at 2 years of age showed cognitive delay (corresponding to 1 year and 6 months). He was subjected to speech therapy due to difficulties related to sensory-motor aspects and oral language. According to a clinical assessment at 4 years of age, despite having communicative intent, language expression was quite restricted. He also had deficits in psychomotor and cognitive executive function that improved with time, especially regarding sensory integration, and he presented an attention deficit. At 5 years of age, an evaluation of language and cognitive development was performed using the Protocol of Observation Behavioral [2]. The examinations revealed the following: limited oral language, with attempts to engage in dialogue; language disorder, especially in expressive language; deficit in motor skills and difficulties in the understanding and execution of tasks and games. With respect to activities of daily living, he showed autonomy in eating and dressing.

At 6 years and 10 months of age, he measured $125 \mathrm{~cm}$ in height $\left(50^{\text {th }}-75^{\text {th }}\right.$ percentile), weighed $26 \mathrm{~kg}\left(50-75^{\text {th }}\right.$ percentile) and had an occipital frontal circumference (OFC) of $52 \mathrm{~cm}\left(25^{\text {th }}-50^{\text {th }}\right.$ percentile). Dysmorphological examination revealed low-set ears with prominent helices and lobules, hypertelorism (ICD $3.5 \mathrm{~cm}$, >97 $7^{\text {th }}$ percentile), bushy eyebrows, short nose with anteverted nostrils, deep nasolabial furrows, small and open mouth with an open bite and a thin vermilion, a prominent Cupid's bow of the upper lip and a prominent and everted lower lip. Mild micrognathia was also observed (Figure 1).

The propositus attends a regular school with support. He communicates well with colleagues and teachers, and he is able to express his wishes through language and to understand simple conversation and demands. Further examinations revealed the following: Magnetic resonance imaging (MRI) showed an intact corpus callosum and a small region of ischemia in the glyptic cavity of the cerebellar region. Electroencephalography (EEG) and audiometry results were normal, and he showed no vision problems.

\section{Results}

With regard to cytogenetic and molecular examinations, the deletion was initially identified through G-banding. The karyotype was interpreted as 46,XY,del(14)(q31). However, fluorescence in situ hybridization (FISH) performed in the proband showed that there was no loss of the terminal region of chromosome 14 (band 14q32). The precise characterization of the deletion using oligonucleotide aCGH showed a loss of genomic material corresponding to an interstitial deletion in the long arm of chromosome 14, segment q24.3-q31.3, of approximately 13.11 Mb (UCSC Genome Browser on Human Feb. 2009 (GRCH37/hg19). Arr 14q24.3q31.3 (76,211,806-89,327,656) $\times 1$ (Figure 2). The parental karyotypes were normal.

\section{Discussion}

Excluding pseudogenes, chromosome 14 presents a mean gene density of 10 genes per $\mathrm{Mb}$ (850 genes per $85 \mathrm{Mb}$ ), which is close to the mean value estimated for the whole human genome (9.3-10.8 genes per $\mathrm{Mb})$ [3].

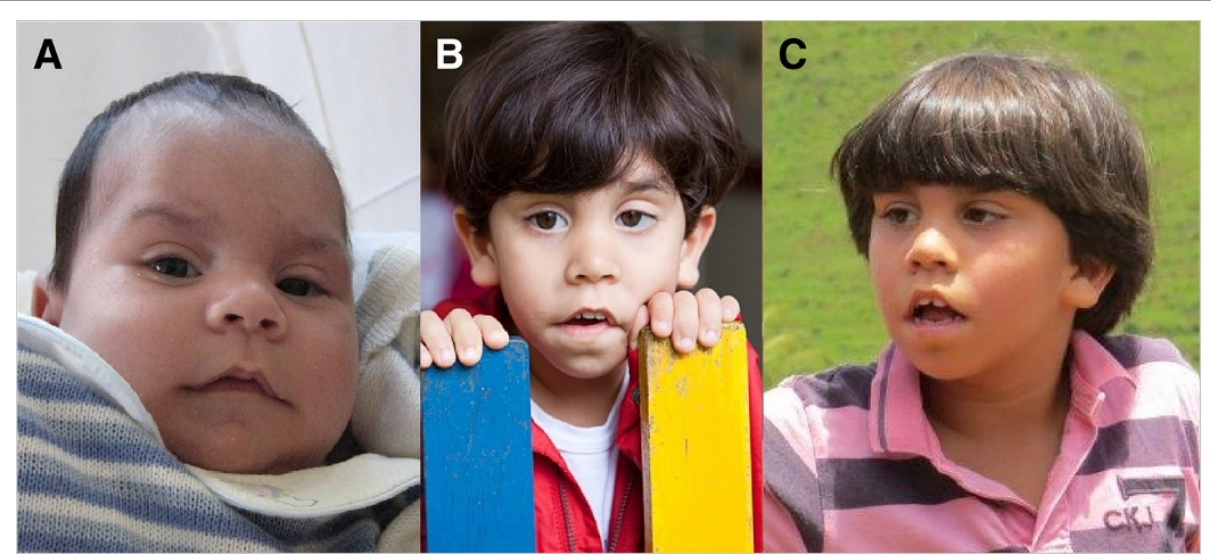

Figure 1 Patient at the ages of 2 months (A), 3 years and 5 months (B) and 6 years and 10 months (C). Note the short upturned nose, deep philtrum, thin vermillion of the upper lip and prominent earlobes. 


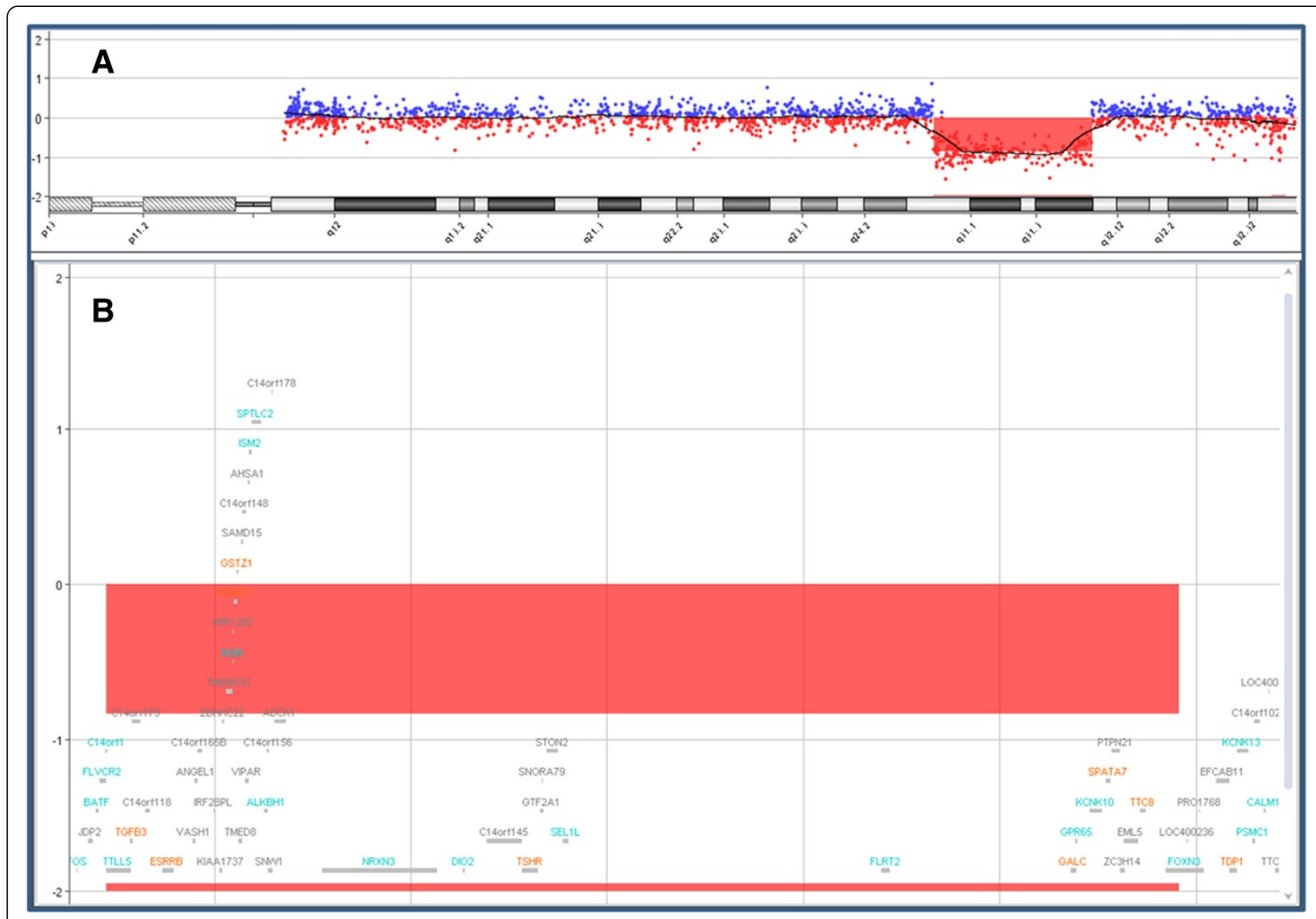

Figure 2 Chromosome 14 aCGH profile of the patient (in red) and a reference DNA sample from a normal male (in blue). The figure shows (A) a copy number loss corresponding to the segment 14q24.3-q31.3 in a genomic segment with the median log2 ratio shifted to -0.8 (red line). The probe log2 ratios were plotted according to genomic coordinates (based on the UCSC Genome Browser, February 2009, NCBI Build 37 reference sequence). In (B), detail of the 14q24.3-q31.3 region showing the deleted region of $\sim 13 \mathrm{Mb}$.

Mutation analysis has revealed 21 genes on this chromosome associated with genetic diseases [4]. Among these, Holt-Oram syndrome or a syndrome similar to Holt-Oram syndrome, has been reported in patients with $14 \mathrm{q}$ deletions. Furthermore, $70 \%$ of those patients fulfilling strict criteria show a mutation in TBX5 on 12q24.1. Thus, there might be a second locus for this syndrome at $14 \mathrm{q} 23.3 \mathrm{q} 31.1$ [5].

The propositus presented with mild to moderate developmental delay, normal growth and a pattern of indistinct minor dysmorphic signs in the absence of organ malformations. For a comparison with previously reported patients with similar or overlapping deletions spanning at least $10 \mathrm{Mb}$ (see Table 1, in order from proximal to distal from the proximal breakpoint), we excluded reports in which the breakpoints were determined only through chromosome banding because it is well known that such methods can provide imprecise determinations leading to incorrect interpretations (for example, a deletion classified as terminal may turn out to be interstitial, as in our proband, and vice versa). Our patient was the first to be subjected to aCGH analysis of the deleted segment. In contrast, using FISH with only a few and mostly flanking markers, it is possible to overlook non-deleted or even duplicated stretches of DNA within a deleted segment, especially in instances of ring chromosomes [6].

Table 1 shows that except for the patient described by LeMeur [5], the proximal breakpoints were quite similar in all patients, ranging from bp 73.942 .355 [7], patient 25 to $77,867,749$ [7], patient 22, whereas the distal breakpoints differed considerably, from $88,488,190[8,9]$ to 98.771.224 $[1,10]$. However, these represent the minimal deleted segments because the space between the last or first present marker and the first or last deleted marker was quite different, and some markers were not precisely mapped. In addition, findings present in only one patient were listed separately, and comparison was limited by the uncertainty of whether dysmorphic findings not described in the different case reports were absent or not considered worth mentioning.

Our comparison of clinical features revealed that neurodevelopmental features such as developmental delay, 
Table 1 Comparison of the clinical features of patients with interstitial 14q deletions including the segment $14 q 23.3$ to $14 q 31.1$

\begin{tabular}{|c|c|c|c|c|c|c|c|c|}
\hline Feature & 1 Le Meur & 2 Zollino, case 25 & 3 Propositus & 4 Karnitis, Byth & 5 Cingöz & 6 Schlade & 7 Zollino 22 & Total \\
\hline Proximal breakpoint & q23.3 & q24.3 & q24.3 & q24.3 & q24.3 & q24.3 & q24.3 & \\
\hline Distal breakpoint & q31.1 & $\mathrm{q} 32.13$ & q31.3 & q31.3 & q32.2 & q32.13 & q31.11 & \\
\hline Size of the deletion in $\mathrm{Mb}$ & 13.937 .056 & 20.971 .834 & 13.115 .851 & 11.665 .854 & 21.545 .793 & 18.576 .858 & 13.981 .234 & \\
\hline \multirow[t]{2}{*}{ Minimal deletion (base pairs) } & 67.736 .534 & 73.942 .355 & 76.211 .806 & 76.822 .337 & 77.226 .431 & 77.823 .431 & 77.867 .749 & \\
\hline & 81.673 .589 & 94.914 .188 & 89.327 .656 & 88.488 .190 & 98.771 .224 & 96.400 .270 & 91.848 .982 & \\
\hline Technique used & $\mathrm{FISH} / \mathrm{BACS}$ & $\mathrm{FISH} / \mathrm{BACS}$ & $\mathrm{aCGH}$ & $\mathrm{FISH} / \mathrm{BACS}$ & $\mathrm{FISH} / \mathrm{BACS}$ & $\mathrm{FISH} / \mathrm{BACS}$ & $\mathrm{FISH} / \mathrm{BACS}$ & \\
\hline Age at last examination (years) & $6 / 12$ & 18 & $69 / 12$ & $36 / 12$ & 10 & 3 & 19 & - \\
\hline Developmental delay & + & ++ & + & + & + & + & ++ & $7 / 7$ \\
\hline Intellectual impairment & & ++ & + & + , mild & + & + & ++ & $7 / 7$ \\
\hline Language delay & & + & + & & + & + & + & $6 / 6$ \\
\hline Postnatal growth retardation & & + & & - & + & + & & $4 / 6$ \\
\hline Muscular hypotonia & + & + & + & & + & + & + & $7 / 7$ \\
\hline Microcephaly postnatally & & + & & & - & + & - & $3 / 4$ \\
\hline Ocular hypertelorism & + & & + & + & + & & & $5 / 5$ \\
\hline Inner epicanthic folds & & & + & + & + & + & & $5 / 5$ \\
\hline Ptosis of eyelids & & + & & + & + & & & $3 / 6$ \\
\hline Downslant/palpebral fissures & + & & + & + & - & & & $3 / 4$ \\
\hline Flat/depressed nasal bridge & & & + & + & + & & & $3 / 3$ \\
\hline Strabismus & & + & & + & & & & \\
\hline Short/bulbous nose & + & & + & + & + & + & & $5 / 5$ \\
\hline Deep/broad philtrum & + & & + & & & & & $2 / 2$ \\
\hline Thin vermilion of the upper lip & + & & + & + & + & & & $4 / 4$ \\
\hline High arched palate & & & + & + & - & & & $2 / 3$ \\
\hline Abnormal dentition & & & + & + & - & & & $2 / 3$ \\
\hline Micro-/retrognathia & + & & & + & - & + & & $3 / 4$ \\
\hline Pointed chin & & & + & & + & & & $2 / 3$ \\
\hline Dysplastic/low-set ears &,+ asymm. & & + & + & + & + & & $6 / 6$ \\
\hline
\end{tabular}


Table 1 Comparison of the clinical features of patients with interstitial 14q deletions including the segment $14 q 23.3$ to $14 q 31.1$ (Continued)

Scoliosis $+$

Congenital heart defect

Hearing impairment

$+(?)$

Findings in single patients

Radial a/hypoplasia cleft

palate, mild ventricular

$+$

dilatation, mate

Myopia, aggressivity balanced insertion

Breech delivery

central lower incisor,

transverse palmar

Blepharo-phimosis,

cupid's bow

crease left

+: present; -: absent, empty: not described Patients: 1. [5] 2. [7], case 25; 3. Present case; 4. [8,9]; 5. [1]; 6. [10]; 7. [7], case 22. 
muscular hypotonia and language delay were quite consistent, as were some frequent and non-specific dysmorphic signs including hypertelorism, inner epicanthic folds, short and bulbous nose with a depressed bridge, thin upper lip and dysplastic ears. However, malformations were inconsistently found, as heart defects were only found in 3/6 patients, and different defects were observed in one patient each. Hearing impairment was reported 4 times, but the other studies did not report on the presence or absence of hearing impairment, and in the reported cases, the type was conductive and sensoryneural, with 2 instances each.

The patient with the greatest accumulation of congenital malformations had at least $6 \mathrm{Mb}$ deleted proximal of the deletion in the other patients [5]. We did not include the following two patients in the comparison. First, Vaags et al. [11] reported a patient with a very small deletion $(0.063 \mathrm{Mb})$ inside that detected in our propositus; this patient had Asperger syndrome with NRXN3 deletion. Although NRXN3 is associated with autism [12] and lies inside our reported deletion, our propositus did not display features of autism. Second, Shimada et al. [12] described a 2-year-old boy with growth and severe mental retardation, a dysmorphic pattern comparable to that observed in our patient and MRI findings of leukodystrophy. This deletion spanned $2.0 \mathrm{Mb}$, of which $0.8 \mathrm{Mb}$ overlapped with the proximal deleted region in our patient. This patient was found to have a deletion of $E I F 2 B 2$, a gene associated with leukodystrophy, which maps outside the deletion in our propositus, who consequently does not show similar neurologic symptoms.

Table 2 lists the genes with only one copy in the propositus. The list shows that mutations of some of these genes, including TTC8 (Bardet-Biedl syndrome 8), POMT2 (Walker-Warburg syndrome), GALC (Krabbe disease), GSTS1 (Tyrosinemia Ib), and SPATA7 (Leber amaurosis

Table 2 An assembly of genes deleted in the present patient according to the Online Mendelian Inheritance in Man (OMIM) annotation

\begin{tabular}{|c|c|c|c|}
\hline Gene & $\begin{array}{l}\text { OMIM } \\
\text { annotation }\end{array}$ & Name/Possible function & Associated syndromes \\
\hline FLRT2 & 604807 & Fibronectin-like domain-containing leucine-rich transmembrane protein 2 & - \\
\hline C14orf4 & 611720 & Chromosome 14 open reading frame 4. & - \\
\hline SPTLC2 & 605713 & $\begin{array}{l}\text { Serine palmitoyltransferase, long-chain base subunit } 2 \text {. } \\
\text { Sphingolipid biosynthesis. }\end{array}$ & Neuropathy, hereditary sensory, type IC. \\
\hline ESRRB & 602167 & Estrogen-related receptor beta. & Deafness, autosomal recessive 35 . \\
\hline NRXN3 & 600567 & Neurexin III. Polymorphic cell surface protein expressed in neurons. & - \\
\hline GPR65 & 604620 & G protein-coupled receptor 65. & - \\
\hline TGFB3 & 190230 & Transforming growth factor beta-3. & $\begin{array}{l}\text { Arrhythmogenic right ventricular } \\
\text { dysplasia 1; Rienhoff Syndrome }\end{array}$ \\
\hline TTLL5 & 612268 & $\begin{array}{l}\text { Tubulin tyrosine ligase-like family, member } 5 \text {. Role in } \\
\text { glucocorticoid-mediated induction and repression. }\end{array}$ & Cone-rod dystrophy 19 \\
\hline TTC8 & 608132 & Tetratricopeptide repeat domain 8. & Bardet-Biedl syndrome 8. \\
\hline FOXN3 & 602628 & Forkhead box N3. & - \\
\hline ISM2 & 612684 & $\begin{array}{l}\text { Isthmin 2, zebrafish homolog. Secreted proteins with diverse } \\
\text { functions such as cell adhesion, cell angiogenesis, and } \\
\text { patterning of developing nervous system. }\end{array}$ & - \\
\hline KCNK10 & 605873 & Potassium channel, subfamily K, member 10 . & - \\
\hline POMT2 & 607439 & Protein o-mannosyltransferase 2. & Walker-Warburg syndrome. \\
\hline $\mathrm{DlO} 2$ & 601413 & $\begin{array}{l}\text { Deiodinase, iodothyronine, type II. A selenoprotein that catalyzes } \\
\text { the } 5 \text {-prime deiodination of thyroxine (T4) to generate an active } \\
\text { thyroid hormone,3,3-prime, } 5 \text { triiodothyronine (T3). }\end{array}$ & - \\
\hline GALC & 606890 & Lysosomal enzyme involved in the catabolism of galactosylceramide. & Krabbe disease. \\
\hline GSTZ1 & 603758 & Tyrosinemia, type lb. & Tyrosinemia, type lb. \\
\hline ALKBH1 & 605345 & $\begin{array}{l}\text { AlkB, E. coli homolog. Protects cells from mutation and cell death } \\
\text { caused by SN2-type alkylating agents. }\end{array}$ & - \\
\hline NGB & 605304 & Neuroglobin. Lower resistance to ischemia and neurofibrillary tangles. & Alzheimer disease. \\
\hline TSHR & 603372 & Thyroid stimulating hormone receptor & Hyperthyroidism,familial gestational. \\
\hline SPATA7 & 609868 & Spermatogenesis associated 7 & $\begin{array}{l}\text { Leber congenital amaurosis } 3 \\
\text { Retinitis pigmentosa }\end{array}$ \\
\hline SEL1L & 602329 & Suppressor of lin-12-like (C. elegans) & - \\
\hline
\end{tabular}


3), produce well-known clinical entities. However, findings characteristic for these conditions are not present in our propositus because hemizygosity would not cause the condition unless the remaining allele carries a mutation or in the case of uniparental disomy. Except for NRXN3 and EIF2B2 (see above), the genes listed in Table 2 are not known to cause specific phenotypes if one allele is absent. This is different from more proximal deletions that cause anophthalmia, cataract (SIX1, BMP4)), hearing loss (OTX2), abnormal pituitary function (SIX4 and SIX6) and polydactyly, all due to hemizygosity of the related genes [13-16]. In patients with deletions distal from that in the propositus and mostly terminal, including ring chromosomes, the clinical patterns tend to be indistinct, mostly showing patterns of dysmorphic signs $[17,18]$. One exception is the case of a mother and daughter who both showed hemifacial microsomia [19]; however, the latter could theoretically be independent of the small deletion.

Genomic imprinting could theoretically cause part of the clinical picture of our propositus. Sutton and Schaffer [20] suggested that $14 q 23-q 32$ is likely an area where imprinted genes may reside because distinct phenotypes have been associated with both maternal and paternal uniparental disomy (UPD) for this chromosome. However, according to the authors, these features mapped to other segments, and they were not present in the propositus. Unfortunately, we could not determine the parental origin of the deletion in our propositus. Generally, most interstitial deletions are paternal in origin. However, because maternal UPD is correlated with profound intrauterine and postnatal growth deficiency and early puberty, loss of a critical imprinted segment in the region 14q24-q31 is unlikely because the propositus does not show this key feature. In addition, the clinical picture of paternal UPD 14 is more severe and less consistent; therefore, a comparison with our patient was not possible.

\section{Conclusions}

In summary, the clinical findings in our propositus compared to those in patients with similar deletions show that deletion of the segment 14q24.3-q31.3 is accompanied by a pattern of developmental delay, muscular hypotonia and a relatively non-specific pattern of dysmorphic findings. Thus, it would be difficult or even impossible to recognize similar cases on the basis of clinical findings alone.

\section{Methods}

Standard GTG banding was performed at a resolution of 400-550 bands on metaphase chromosomes from peripheral blood lymphocytes of the patient and his parents. Molecular karyotyping was performed on the proband using through whole-genome array-CGH using a 60mer oligonucleotide-based microarray with a theoretical resolution of $40 \mathrm{~kb}(8 \times 60 \mathrm{~K}$, Agilent Technologies Inc. Santa Clara, CA) (Figure 2A,B). Labeling and hybridization were performed following the protocols provided by the manufacturers. Images of the arrays were taken using a microarray scanner (G2600D) and processed using Feature Extraction software (v9.5.1), both from Agilent. The raw data were analyzed by Agilent Cytogenomics v2.7.8.0 software with the statistical algorithm ADM-2, using a threshold of 6.0 and a 4-probe minimum aberration call.

\section{Consent}

Written informed consent was obtained from the patient's parents for publication of this Case report and any accompanying images. A copy of the written consent is available for review by the Editor-in-Chief of this journal.

\section{Competing interests}

The authors declare that they have no competing interests.

\section{Authors' contributions}

All authors have made substantial contributions to conception and design, acquisition of data, analysis and interpretation of data. All authors have been involved in drafting the manuscript and revising it critically for important intellectual content. All authors read and approved the final manuscript.

\section{Acknowledgments}

The authors thank the patient's family for their kind cooperation in all stages of this study. The investigation was supported by the Brazilian Network of Reference and Information in Microdeletion Syndromes (RedeBRIM), CNPq/ Brazil grant number: 402012/2010-0 and Swiss National Foundation, Grant number: 320030-113635

\section{Author details}

${ }^{1}$ Medical Genetics Service, Hospital de Clínicas de Porto Alegre, Rua Ramiro Barcelos 2350, 90035-003 Porto Alegre, RS, Brazil. Postgraduate Program in Genetics and Molecular Biology, UFRGS, Porto Alegre, RS, Brazil. ${ }^{3}$ Institute of Medical Genetics, University of Zurich, Zurich, Switzerland. ${ }^{4}$ Laboratory of Human Genetics and Mutagenesis; Genetics \& Society Program, Institute of Biology, Federal University of Bahia (UFBA), Salvador, Bahia, Brazil.

${ }^{5}$ Postgraduate Studies Program in Interactive Processes of Organs and Systems, Institute of Health Sciences, Federal University of Bahia (UFBA), Salvador, Bahia, Brazil.

Received: 24 August 2014 Accepted: 20 October 2014 Published online: 19 November 2014

\section{References}

1. Cingöz S, Blache I, Bjerglund L, Ropers $H-H$, Tommerup $N$, Jensen $H$, Brondum-Nielsen K, Tümer Z: Interstitial deletion of 14q24.3-q32.2 in a male patient with plagiocephaly, BPES features, developmental delay, and congenital heart defects. Am J Med Genet Part A 2011, 155:203-206.

2. Zorzi JL, Hage SRV: PROC- Protocolo de observação comportamental: avaliação de linguagem e aspectos cognitivos infantis. São José dos Campos: Pulso Editorial; 2004.

3. Heilig R, Eckenberg R, Petit JL, Fonknechten N, Da Silva C, Cattolico L, Levy M, Barbe V, de Berardinis V, Ureta-Vidal A, Pelletier E, Vico V, Anthouard V, Rowen L, Madan A, Qin S, Sun H, Du H, Pepin K, Artiguenave F, Robert C, Cruaud C, Brüls T, Jaillon O, Friedlander L, Samson G, Brottier P, Cure S, Ségurens $B$, Anière $F$, et al: The DNA sequence and analysis of human chromosome 14. Nature 2003, 421(6923):601-7.

4. Kamnasaran D, Cox DW: Current status of human chromosome 14. J Med Genet 2002, 39:81-90.

5. Le Meur N, Goldenberg A, Michel-Adde C, Drouin-Garraud V, Blaysat G, Marret S, Amara SA, Moirot H, Joly-Hélas G, Mace B, Kleinfinger $P$, 

deletion in a boy with features of Holt-Oram syndrome. Am J Med Genet A 2005, 2005(134):439-442.

6. Rossi E, Riegel M, Messa J, Gimelli S, Maraschio P, Ciccone R, Stroppi M, Riva P, Perrotta C, Mattina T, Baumer A, Kucinskas V, Castellan C, Schinzel A, Zuffardi O: Duplications in addition to terminal deletions are present in a proportion of ring chromosomes: clues to the mechanisms of formation. J Med Genet 2008, 45:147-54

7. Zollino M, Seminara L, Orteschi D, Gobbi G, Giovannini S, Della Giustina E, Frattini D, Scarano A, Neri G: The ring 14 syndrome: clinical and molecular definition. Am J Med Genet A 2009, 149:1116-1124.

8. Karnitis SA, Burns K, Sudduth KW, Golden WL, Wilson WG: Deletion (14) (q24.3q32.1): evidence for a distint clinical phenotype. Am J Med Genet 1992, 44:153-157.

9. Byth BC, Costa MT, Teshima IE: Molecular analysis of three patients with interstitial deletions of chromosome band 14q31. J Med Genet 1995, 32:564-567.

10. Schlade-Bartusiak K, Macintyre G, Zunich J, Cox DW: A child with deletion (14)(q24.3q32.13) and auditory neuropathy. Am J Med Genet A 2008, 146:117-123.

11. Vaags AK, Lionel AC, Sato D, Goodenberger MK, Stein QP, Curran S, Ogilvie C, Ahn JW, Drmio I, Senman L, Chrysler C, Thomoson A, Russel C, Prasad A, Walker S, Pinto D, Marshall C, Stravopoulos D, Zwaigenbaum L, Fernandez BA, Fombonne E, Bolton P, Collier DA, Hodge JC, Roberts W, Szatman P, Scherer SW: Rare deletions at the Neurexin 3 locus in Autism Spectrum Disorder. Am J Hum Genet 2012, 90:133-141.

12. Shimada S, Miya K, Oda N, Watanabe Y, Kumada T, Sugawara M, Shimojima $\mathrm{K}$, Yamamoto T: An unmasked Mutation of EIF2B2 due to submicroscopic deletion of $14 \mathrm{q} 24.3$ in a patient with vanishing white matter disease. Am J Med Genet A 2012, 158:1771-1777.

13. Guilherme RS, Cernach MCSP, Sfakianakis TE, Takeno SS, Nardizza LMM, Rossi C, Bhatt SS, Liehr T, Melaragno MI: A complex chromosome rearrangement involving four chromosomes, nine breakpoints and a cryptic 0.6-Mb deletion in a boy with cerebellar hypoplasia and defects in skull ossification. Cytogenet Genome Res 2013, 141:317-323.

14. Oehl-Jaschkowitz B, Vanakker OM, De Paepe A, Menten B, Martin T, Weber G, Christmann A, Krier R, Scheid S, McNerlan SE, McKee S, Tzschach A: Deletions in 14q24.1q24.3 are associated with congenital heart defects, brachydactyly, and mild intellectual disability. Am J Med Genet A 2014, 164:620-626.

15. Brisset S, Slamova Z, Dusatkova P, Briand-Suleau A, Milcent K, Metay C, Simandlova M, Sumnik Z, Tosca L, Goossens M, Labrune P, Zemankova E, Lebl J, Tachdjian G, Sedlacek Z: Anophthalmia, hearing loss, abnormal pituitary development and response to growth hormone therapy in three children with microdeletions of 14q22q23. Mol Cytogenet 2014, 7:17-23.

16. Martinez-Frias ML, Ocejo-Vinyals JG, Arteaga R, Martinez-Fernandez ML, MacDonald A, Pérez-Belmonte E, Bermejo-Sanchez E, Martinez S: Interstitial deletion 14q22.3q23.2: genotype-phenotype correlation. Am J Med Genet A 2014, 164:639-647.

17. Yen FS, Podruch PE, Weisskopf B: A terminal deletion (14)(q31.1) in a child with microcephaly, narrow palate, gingival hypertrophy, protuberant ears and mild mental retardation. J Med Genet 1989, 26:130-133.

18. Piccione M, Antona V, Scavone V, Nalacarne M, Pierluigi M, Grasso M, Corsello G: Array CGH defined interstitial deletion on chromosome 14: a new case. Eur J Pediatr 2010, 169:845-851.

19. Gimelli S, Cuoco C, Ronchetto P, Gimelli G, Tassano E: Interstitial deletion $14 q 31.1 \mathrm{q} 31.3$ transmitted from a mother to her daughter, both with features of hemifacial microsomia. Hum Genet 2013, 54:361-364.

20. Sutton VR, Schaffer LG: Search for imprinted regions on chromosome 14: comparison of maternal and paternal UPD cases with cases of chromosome 14 deletion. Am J Med Genet 2000, 2000(93):381-387.

doi:10.1186/s13039-014-0077-4

Cite this article as: Riegel et al: Interstitial $14 q 24.3$ to q31.3 deletion in a 6-year-old boy with a non-specific dysmorphic phenotype. Molecular Cytogenetics 2014 7:77.

\section{Submit your next manuscript to BioMed Central and take full advantage of:}

- Convenient online submission

- Thorough peer review

- No space constraints or color figure charges

- Immediate publication on acceptance

- Inclusion in PubMed, CAS, Scopus and Google Scholar

- Research which is freely available for redistribution

Submit your manuscript at www.biomedcentral.com/submit
C) BioMed Central 